\title{
Techno-economic assessment of providing control energy reserves with a biogas plant
}

\author{
Ervin Saracevic $(\bowtie){ }^{1}$, David Woess ${ }^{2}$, Franz Theuretzbacher ${ }^{3}$, Anton Friedl ${ }^{1}$, Angela Miltner ${ }^{1}$ \\ 1 Institute of Chemical, Environmental and Bioscience Engineering, TU Wien, 1060 Vienna, Austria \\ 2 University of Natural Resources and Life Sciences, 1180 Vienna, Austria \\ 3 University of Applied Sciences, 2700 Wiener Neustadt, Austria
}

(c) The Author(s) 2018. This article is published with open access at link.springer.com and journal.hep.com.cn

\begin{abstract}
Grid stability is being challenged by the increasing integration of power plants with volatile power generation into the energy system. Power supply fluctuations must be compensated by energy system flexibility. The storability of the energy carrier enables biogas plants to generate power flexibly. In this study, the technical and economic effects of providing positive secondary control energy reserves with an Austrian biogas plant were assessed. The plant's main focus lies in biomethane production with the option of heat and power generation through combined heat and power (CHP) units. A detailed simulation model of the investigated biogas plant was developed, which is presented in this work. Ex-post simulations of one year of flexible plant operation were conducted with this model. The findings show that the installed biogas storage capacity is sufficient to provide control energy reserves while simultaneously producing biomethane. Profitability of providing control energy reserves largely depends on the prices at the control energy market and on CHP unit start-up costs. A cost efficiency analysis demonstrated that investing in a hot water tank with a volume of $5 \mathrm{~m}^{3}$ for short-term heat storage turned out to be economically viable.
\end{abstract}

Keywords biogas plant, process simulation, control energy reserves, economic assessment, gas storage

\section{Introduction}

Energy system decarbonisation is a central aspect of the global energy policy. In accordance to its energy strategy

Received March 14, 2018; accepted August 25, 2018

E-mail: ervin.saracevic@tuwien.ac.at for 2050, the climate targets of the European Union (EU) for 2030 aim to reduce greenhouse gas emissions by at least $40 \%$ compared to 1990 levels and to increase the share of renewables to at least $27 \%$ of EU energy consumption [1]. Austria's national targets stipulate a $36 \%$ reduction of greenhouse gas emissions compared to 2005 levels. First projections show that current efforts must be enhanced to meet these targets [2].

The increasing integration of renewables into the energy system poses challenges to power grid stability, particularly because the share of power plants with intermittent power generation - mainly wind and photovoltaic power plants - is rising (in this work the term power refers solely to electricity). The installed power capacity of wind power plants in Austria increased from $1.84 \mathrm{GW}$ in 2010 to 4.07 GW in 2016, while the capacity of photovoltaic plants increased from 0.15 to $1.46 \mathrm{GW}$ during the same period [3]. These plants are characterised by a very volatile power generation, which is highly dependent on weather conditions. Increasing fluctuations along with limited predictability of the power supply have resulted in a rising demand for balancing energy. The demand for balancing energy in Austria increased almost proportionally to the installed wind power capacity from $0.68 \mathrm{TWh}$ in 2010 to $1.31 \mathrm{TWh}$ in 2016 [3]. The demand for balancing energy is expected to further rise in the coming decades given the increasing share of power plants with intermittent power generation [4].

Additional technological measures, which provide flexibility in the energy system, are needed to compensate increasing power supply fluctuations. Those measures include the possibility to operate power plants on demand. Biogas plants have a high potential for demand-oriented power generation, as the energy carrier can be stored over a long period [5]. In biogas plants, organic matter is converted to biogas by anaerobic digestion. The biogas is then usually processed in combined heat and power 
(CHP) units. The overall efficiency of energy conversion from biogas to power and heat with CHP units is around $85 \%-90 \%$ [6]. Biogas can alternatively be converted to biomethane through drying of the gas and removal of $\mathrm{CO}_{2}$ and minor components by a gas upgrading process. A summary of common gas upgrading technologies can be found in Miltner et al. [7]. Most biogas plants in Europe are currently designed for continuous power generation as base load power plants. A demand-oriented biogas supply is necessary for flexible power generation, which can be achieved either by biogas storage concepts or concepts for flexible biogas production [8]. Biogas can be stored either on-site at the biogas plant with appropriate gas storage systems or in the natural gas grid after a gas-upgrading step. In most cases, biogas is stored directly at the plant. Flexible biogas production is an alternative that can reduce necessary biogas storage capacity and can be achieved by changes to substrate feeding intervals, organic workload or feeding material [9].

Several studies addressing the necessary technical and economic requirements for flexible power generation with biogas plants have been published to date, most originating from Germany. Concepts and technical requirements for biogas plant flexibilisation are discussed in Trommler et al. [10]. A summary of the necessary technical adaptions for flexible power generation with biogas plants can be found in Haering et al. [11]. Several studies that focus on the economics of flexible power generation with biogas plants used process simulation as a tool to assess flexible plant operation scenarios. Gohsen and Allelein [12] developed a market-based optimisation model for investigating different concepts of biogas plants operated as storage power plants. Lauer and Thrän [13] discussed the economic efficiency of reducing surplus generation in the German electricity system through flexible power generation with biogas plants. In Haering et al. [14], an optimisation model was used to maximise revenues from participation in the spot market. Some studies have investigated using flexible biogas production to reduce required biogas storage capacity. Mauky et al. [15] showed that flexible biogas production can be achieved in fullscale biogas plants with no negative effects for the longterm process stability. Hahn et al. [16] performed cost analyses of biogas storing and flexible biogas production concepts. In Barchmann et al. [17], continuous biogas production was compared to flexible biogas production as part of an economic assessment. Grim et al. [18] developed a dynamic biogas plant model and showed that biogas storage requirements can be reduced by feeding management. O'Shea et al. [19] used kinetic models to determine the optimal feeding time at a biogas plant with combined flexible power generation and biomethane production. Only a few studies assessed the participation of biogas plants in the markets for control energy reserves. Control energy reserves in Europe are organised by national transmission system operators (TSO). The TSOs regulate power grid frequency, which must be held at $50 \mathrm{~Hz}$. Power capacities, which are placed on the markets for control energy reserves, must be kept available by the plant operator at all times. Control energy reserves can be subdivided into negative reserves, which are used to reduce power generation on demand and into positive reserves, which give the TSO the option to increase power generation when necessary. Moreover, they are distinguished in primary, secondary and tertiary reserves depending on the power generation unit's required reaction time. The required reaction time for primary reserves is thirty seconds, while it is five minutes for secondary reserves and fifteen minutes for tertiary reserves [20]. The reaction and start-up times for CHP units enable most biogas plants to participate in secondary and tertiary control energy reserve markets. Hochloff and Braun [21] investigated the potential profitability of participating in electricity spot markets and in markets that organise tertiary control energy reserves with biogas plants that have invested in excess CHP unit capacity. Hochloff and Holzhammer [22] assessed the economic feasibility of providing secondary control energy reserves with a biogas plant. An integrated simulation model was developed by Lauer et al. [23] for the economic and ecologic assessment of flexible power generation concepts with biogas plants. The model was used to evaluate the economic viability of various scenarios for flexible power generation, which included participation in the spot market and the market for secondary control energy reserves.

The technical and economic feasibility of providing control energy reserves with a biogas plant that primarily focuses on biomethane production has not yet been investigated in detail. In this work, process simulation is used to assess the technical and economic consequences of providing control energy reserves while simultaneously producing biomethane with a biogas plant. A detailed simulation model of the investigated biogas plant is presented, which allows dynamic simulation of flexible plant operation. One year of plant operation is simulated ex-post assuming participation in the market for control energy reserves and compared to the current state of operation. The technical and economic feasibility of providing control energy reserves is assessed and the optimal heat storage capacity is determined in course of a cost efficiency analysis.

\section{Methods}

This work investigates an Austrian biogas plant for waste treatment. The plant's main focus lies in biomethane production through a membrane separation process. The plant has two CHP units (836 kW and $526 \mathrm{~kW})$ that are currently only operated in case of malfunction or maintenance times for the biogas-upgrading units. This study assesses the feasibility of providing positive control 
energy reserves by starting the CHP units when control reserves are activated by the TSO.

Figure 1 shows the current state of operation at the biogas plant (biomethane production) and the state of biogas plant operation, which is investigated in this study (biomethane production and provision of control energy reserves). The plant's installed biogas storage capacity $\left(4800 \mathrm{~m}^{3}\right)$ is designed to store approximately $6^{-} 8 \mathrm{~h}$ of produced biogas under nominal load. The plant's yearly production is about $5.2 \mathrm{Mm}^{3}$ biogas.

\subsection{Simulation model of the biogas plant}

A dynamic simulation model of the described biogas plant was developed to assess the technical and economic consequences of flexible biogas plant operation. The plant model was developed in the process simulation program IPSEpro 7.0. The program's focus lies in simulating energy systems and an equation-oriented approach is used for calculating flow sheets that are developed in the simulation environment. Dynamic time stepping is applied in the program for time-dependent simulations.

Figure 2 shows the developed biogas plant simulation model, which is based on mass and energy balances. Real plant data, which was collected during a monitoring in 2015, was used to calibrate the model. The flow sheet setup consists of units for biogas production (hygienisation tank, mixing tank and fermenters), a biogas storage unit, units for biogas upgrading (desulphurisation, condenser, compressor and gas permeation unit), two CHP units and a heat storage unit. Biogas is produced in the fermenters and stored in a biogas storage, from where it is transferred to the gas upgrading units for biomethane production or to the CHP units for power and heat generation. Process water is used to cool the CHP units. The heated water is stored in a heat storage, from where it is transferred to the biogas production units and used to cover the heat demand for hygienisation of the substrates and heating of the fermenters. The cooled process water is then again used to cool the CHP units. The biogas-upgrading units were modelled by simple black-box units. Particular attention was given to the modelling of the biogas storage unit and the CHP units, as these are essential units for flexible power generation.

A biogas storage model was developed that allows for calculating the gas storage level. The mass balance of the biogas storage unit is shown in Eq. (1).

$$
\frac{\mathrm{d} m}{\mathrm{~d} t}=\dot{m}_{\mathrm{IN}}-\dot{m}_{\mathrm{CHP}}-\dot{m}_{\mathrm{CH}_{4}} \text {. }
$$

Biogas that is produced in the fermenters $\left(\dot{m}_{\mathrm{IN}}\right)$ is either stored in the biogas storage or processed to the CHP units $\left(\dot{m}_{\mathrm{CHP}}\right)$ or gas-upgrading units $\left(\dot{m}_{\mathrm{CH}_{4}}\right)$. Biogas is transferred to the CHP units in case of power generation, i.e., when control energy reserves are activated by the TSO. The biogas volume flow to the biogas-upgrading units was

\section{Current state of operation}
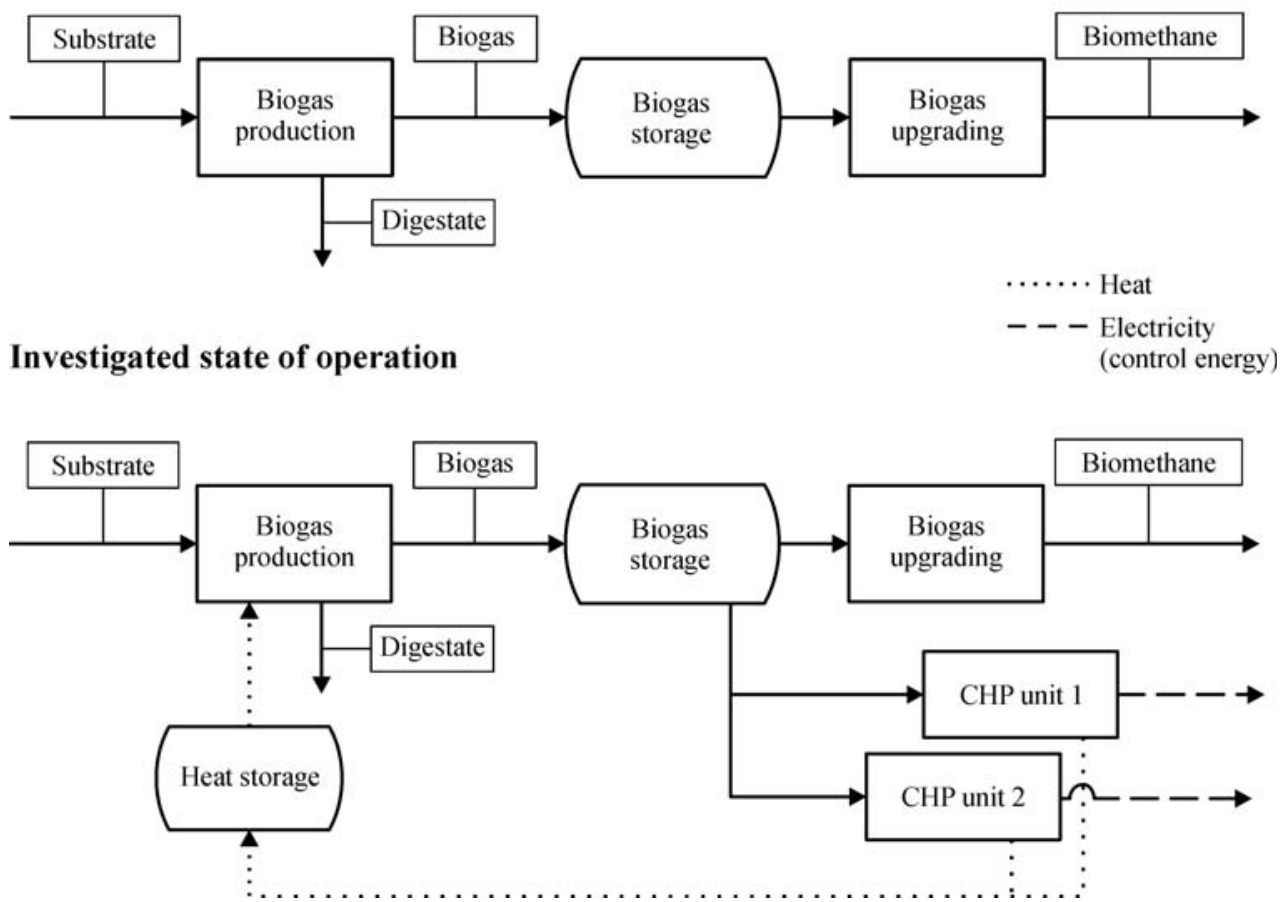

Fig. 1 Current state of operation at the biogas plant (biomethane production) and investigated state of operation (biomethane production and provision of control energy reserves) 
dependent on the biogas production and at least $200 \mathrm{~m}^{3} \cdot \mathrm{h}^{-1}$ to ensure a continuous biomethane production. The initial biogas storage level was set to be half of the set maximum level of $3800 \mathrm{~m}^{3}$.

The two CHP units models in Fig. 2 are based on mass and energy balances. The electrical efficiency curves that describe the relation between electric efficiency and CHP unit load point were defined and implemented in the models. Real plant data from the investigated biogas plant was used for calibration and validation of the model. The plant data was implemented in IPSEpro and electrical efficiency was calculated for every measurement point by calculating mass and energy balances. A detailed description of the calibration process can be found in [24]. Figure 3 shows the results of the model validation.
A comparison of simulated power values to power measurement at the biogas plant is shown in Fig. 3(A). The simulated values evidently show a good correlation to the measured data with a coefficient of determination (Eq. (2)) of 0.995 for the first engine $(836 \mathrm{~kW})$ and 0.997 for the second engine (526 kW) (Fig. 3(B)):

$$
R^{2}=1-\frac{\Sigma\left(y_{i}-\hat{y}_{i}\right)^{2}}{\Sigma\left(y_{i}-\bar{y}\right)^{2}},
$$

where $R^{2}$ is coefficient of determination, $y_{i}$ standardised measured value, $\hat{y}_{i}$ standardised simulated value and $\bar{y}$ arithmetic mean of measured values. A more detailed description of the biogas plant's simulation model shown in Fig. 2 can be found in [25].

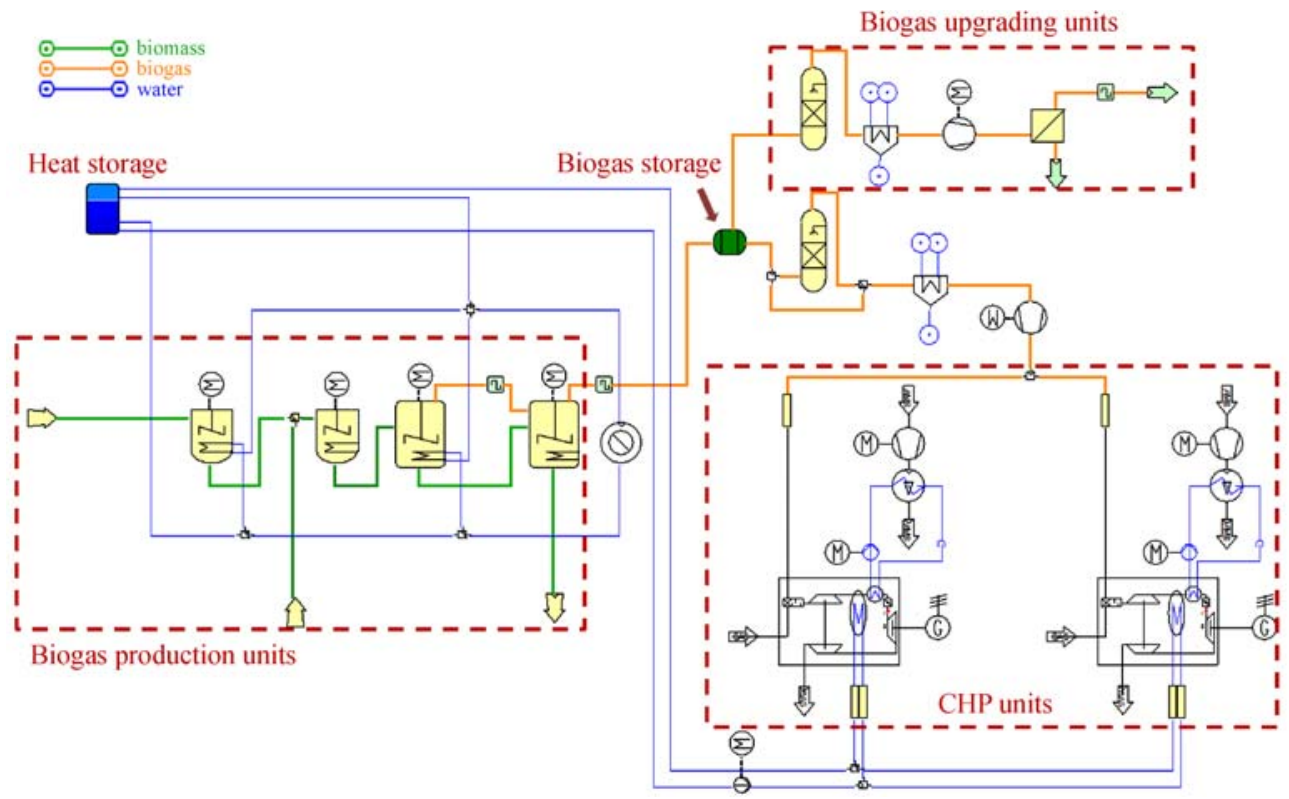

Fig. 2 Simulation model of the investigated biogas plant in IPSEpro 7.0

(A)

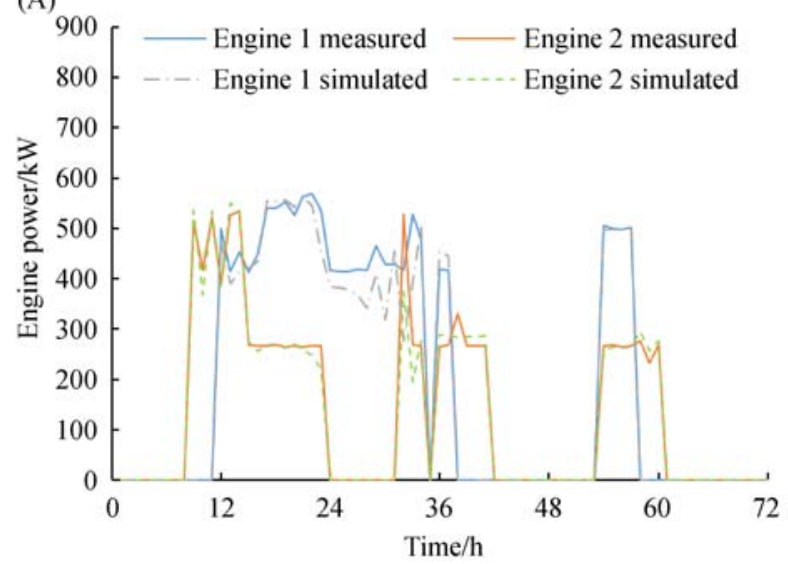

(B)

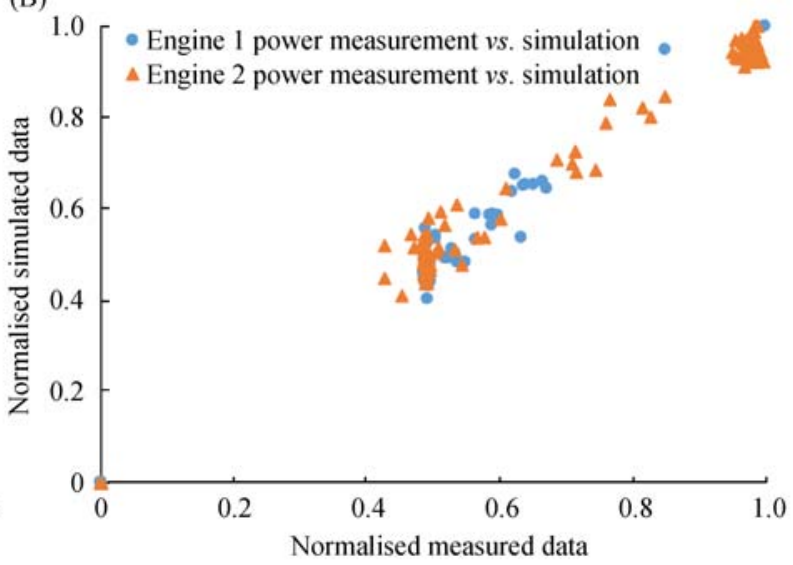

Fig. 3 CHP unit model validation by comparison of measured data to simulated data 


\subsection{Key case study parameters}

This work provides one-year ex-post simulations of biogas plant operation using the simulation model shown in Fig. 2 and assessing the period from mid-July 2016 to mid-July 2017. Two scenarios were simulated and compared with each other: the first scenario represents the current state of operation at the biogas plant (biomethane production) and serves as a reference scenario, while the second scenario assumes participation in the market for positive secondary control energy reserves and simultaneous biomethane production (cf. Fig. 1). Continuous biomethane production is necessary due to gas delivery contracts that must be fulfilled. The market for secondary control energy reserves was selected as the reaction time of the investigated biogas plant's CHP units is sufficient for participation in this market and the prices are currently higher than in the market for tertiary control energy reserves [26]. Data published by the Austrian TSO (APG) and on the platform for allocating control energy reserves [27] was used to determine the times when control energy reserves were activated. Biogas plant operators profit in two ways when providing control energy reserves: they receive compensation for holding power capacities available (power price) and a payment for the actually provided power (energy price). The economic evaluation in this work uses a power price, which is based upon the average power price that was granted for every tender for control energy reserves and an energy price of $200 € \cdot \mathrm{MW} \cdot \mathrm{h}^{-1}$ (cf. Table 1 ). The economic evaluation assumed that the total installed power capacity at the biogas plant (1.36 MW) was used to provide positive secondary control energy reserves and that the total capacity was activated at every call-of order for $3 \mathrm{~min}$.
The annuity method was applied to determine the economic efficiency of installing a heat storage unit (hot water tank) for optimal heat utilisation at the biogas plant. The aim of this cost efficiency analysis was to determine the optimal heat storage volume for short-term heat storage. The annuity method is described in VDI 2067 [28]. This method is used to compare one-time and repeated costs to investment revenues over a certain amortisation period. For the investment costs, a cost function developed by the Institute for Energy and Environmental Technology in Duisburg was used [29] and discounted using the Chemical Engineering Plant Cost Index (CEPCI) [30]. Profitability was defined as the ratio of annuity and investment costs and was used as a simplified measure for the economic assessment; a negative profitability equals an unprofitable investment. The assumptions of the cost-efficiency analysis and further key parameters of the economic assessment are summarised in Table 1.

\section{Results}

The scenario that was investigated in this study assumes participation in the market for secondary positive control energy reserves while simultaneously producing biomethane. It was compared to a reference scenario that represents the biogas plant's current state of operation, which is designed for biogas upgrading to biomethane only, without any heat and power generation. This approach assesses the effects on the economic viability and technical units of the biogas plant while providing control energy reserves with the CHP units.

Table 1 Parameters of the economic assessment

\begin{tabular}{|c|c|c|c|}
\hline Parameter & Value & Unit & Source \\
\hline Costs and revenues of biogas plant & & & Information by plant operator \\
\hline Energy price for control energy reserve & 200 & $€ \cdot \mathrm{MW} \cdot \mathrm{h}^{-1}$ & \\
\hline Electricity cost of biogas plant & 60 & $€ \cdot \mathrm{MW} \cdot \mathrm{h}^{-1}$ & \\
\hline Heat cost of biogas plant & 55 & $€ \cdot M W \cdot h^{-1}$ & \\
\hline Biomethane revenue & 55 & $€ \cdot \mathrm{m}_{\mathrm{N}}^{-3}$ & \\
\hline CHP unit start-up cost & 10 & $€$ & \\
\hline CHP unit maintenance cost & 16.5 & $€ \cdot h^{-1}$ & \\
\hline Power grid utilisation cost & 1.76 & $€ \cdot \mathrm{MW} \cdot \mathrm{h}^{-1}$ & \\
\hline \multicolumn{4}{|l|}{ Cost efficiency analysis for heat storage } \\
\hline Investment costs for hot water tank & $18.18 * V^{a)} \wedge 0.63$ & $€$ & [29] \\
\hline Cost Index & 1.39 & - & {$[30]$} \\
\hline Amortisation period & 15 & Y & \\
\hline Maintenance cost (in $\%$ of investment) & 2 & $\%$ & {$[28]$} \\
\hline Insurance cost (in $\%$ of investment) & 0.5 & $\%$ & {$[28]$} \\
\hline
\end{tabular}

a) V: Volume of hot water tank in litres 


\subsection{Economic characteristics}

Figure 4 shows the additional revenues or losses that are generated through participation at the market for positive secondary control energy reserves and the costs and revenues from power generation. The results demonstrate that the provision of secondary control energy reserves led to profitable results in most of the simulated months. The highest revenue was generated in August 2016 at $4711.57 €$. Revenues of this magnitude are rather small when compared to revenues generated through biomethane production, nevertheless they increase the economic efficiency of the biogas plant. In four of the simulated months, the provision of secondary control energy reserves led to unprofitable results. As Fig. 4 shows, only small revenues could be generated by the power price in these months, which represents the payment for holding power capacities available. The figure also reveals that revenues generated by the energy price, which is the payment for activated reserve, have about the same magnitude as the CHP unit start-up costs. Start-up costs contribute highest to the CHP unit power generation costs and were considered in the economic assessment as every start of an engine reduces its lifespan. Maintenance costs and costs for power grid utilisation were comparably small.

\subsection{Storage capacities}

The biogas storage is of particular importance when providing control energy reserves, as the biogas plant operator does not know beforehand when control energy reserves will be activated. The installed biogas storage capacity at the investigated biogas plant proved sufficient during the simulated period for all months. Figure 5 shows the gas storage level for January 2017, which was the month with most activated control energy reserve and therefore highest effect on the gas storage level.

The provision of control energy reserves can be shown to reduce the gas storage level by a considerable amount whenever control energy reserves were activated, especially at the end of the month. Despite this period with high biogas demand, the installed biogas storage capacity was sufficient to provide biogas for power generation and biomethane production in the simulated period.

Most of the substrate that is used at the investigated biogas plant for waste treatment must be heated up and hygienised until a temperature of $70^{\circ} \mathrm{C}$ is reached before it is processed in the fermenters. For this reason, the plant has a considerably high heat demand. The heat that is produced by the CHP units can be used to partially cover this heat demand. Hot water tanks are used for short-term heat storage at biogas plants for optimal heat integration. A cost efficiency analysis was conducted to assess the economic feasibility of investing into a heat storage and to identify the optimal storage volume. The annuity method was applied to assess a variety of storage volumes calculating a profitability for each of the investigated volumes. Figure 6 shows the results of this analysis. The figure reveals that economic feasibility can only be achieved at a storage volume of $5 \mathrm{~m}^{3}$ with a profitability of 0.0002 . An investment into other heat storage volumes did not turn out to be economically viable due to negative

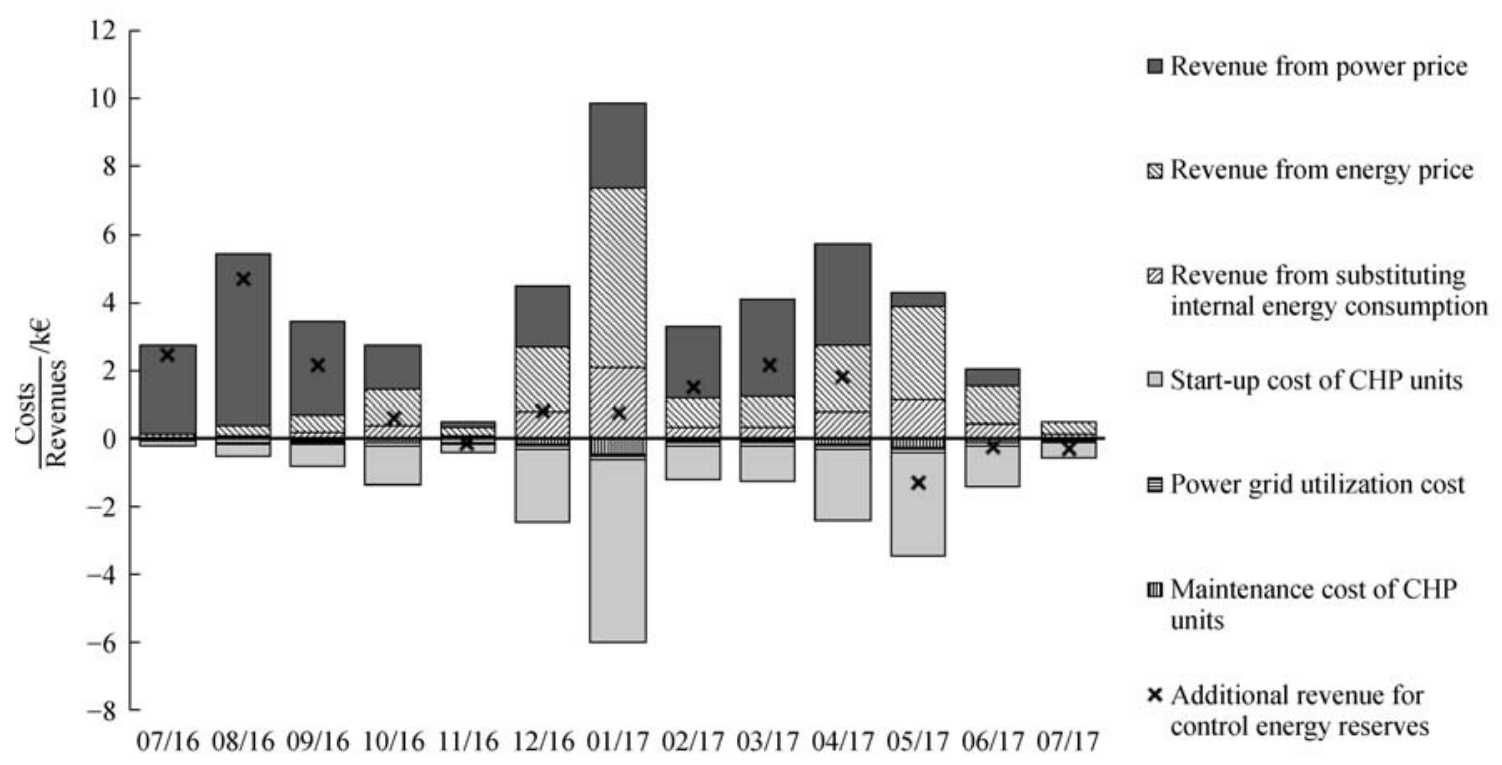

Fig. 4 Additional revenues of providing positive secondary control energy reserves and costs and revenues of power generation with the CHP units 


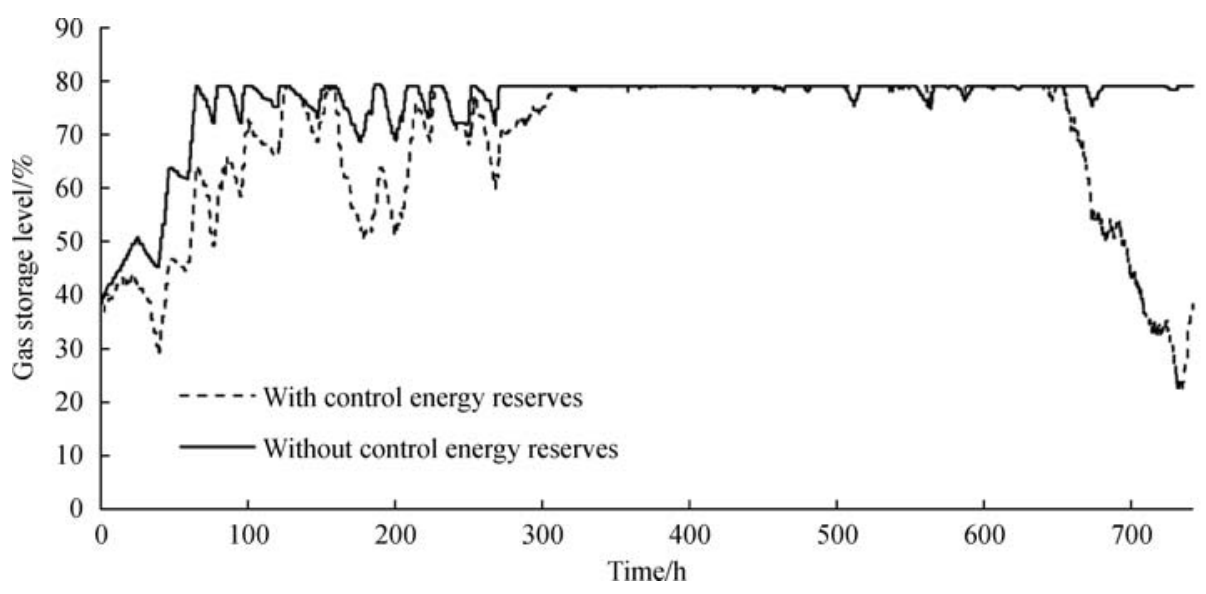

Fig. 5 Simulated gas storage level for January 2017

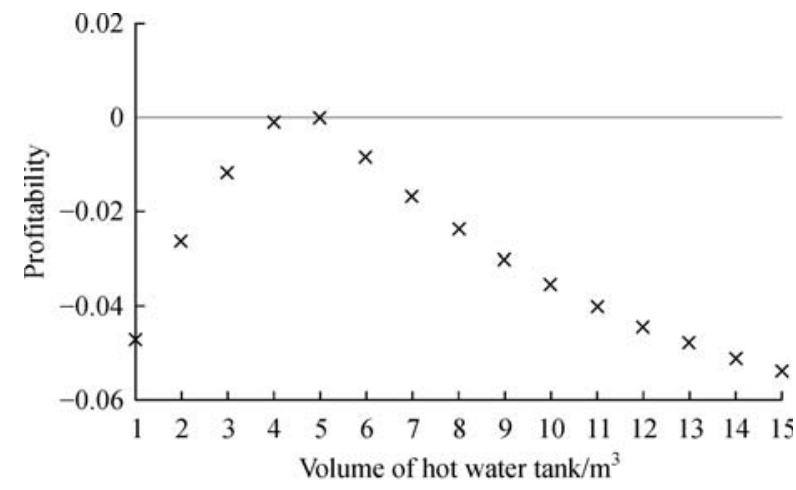

Fig. 6 Results of cost efficiency analysis in regards to hot water tank volume

profitabilities. Approximately 227.09 GJ of heat per year could be additionally used to cover the heat demand of the biogas plant with a storage volume of $5 \mathrm{~m}^{3}$.

\subsection{Discussion}

The profitability of providing control energy reserves depends on several parameters. A sensitivity analysis was used to identify the parameters that have the highest impact on economic characteristics. The results from the analysis are shown in Fig. 7 for January 2017. A 10\% parameter variation was assumed, whereby heat and electricity costs were successively increased by $10 \%$ and maintenance costs, start-up costs and biomethane price were successively decreased by $10 \%$. The figure shows the relative change to additional revenue (Eq. (3)) that can be generated by providing control energy reserves, after each of the parameters was increased/decreased one after the other by $10 \%$.

$$
R C=\left(\frac{R_{\mathrm{VAR}}}{R_{\mathrm{BASE}}}-1\right) \times 100,
$$

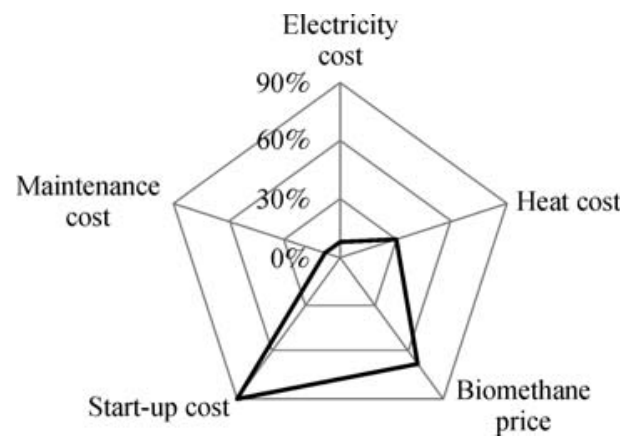

Fig. 7 Relative change to the additional revenue through the provision of control energy reserves after a $10 \%$ parameter variation of costs and revenues for power generation with $\mathrm{CHP}$ units in January 2017

where $R C$ is relative change to additional revenue in $\%$, $R_{\mathrm{VAR}}$ additional revenue after parameter variation, and $R_{\mathrm{VAR}}$ additional revenue before parameter variation (base case).

Figure 7 shows that profitability depends primarily on the CHP unit start-up costs and on the biomethane price, as variations of these parameters have the highest impact on the additional revenue that can be generated by providing control energy reserves with a relative change of $88.6 \%$ and $67.4 \%$, respectively. Maintenance costs of the CHP units and electricity costs do not prove to have a high effect on profitability with a relative change of only $7.6 \%$ and $8.0 \%$, respectively. However, there is a high number of engine starts when providing control energy reserves, which leads to excessive wear of the technical components. It can be assumed that maintenance costs will significantly increase when participating in markets for control energy reserves [14] and therefore have a higher impact on economic outcomes than shown in Fig. 7.

To increase profitability, it is of high interest to minimise CHP unit start-up and maintenance costs. Technical 
measures to reduce mechanical stress during gas engine start-up procedures include pre-heating and pre-greasing the engines as well as using appropriate starting systems [31]. It is recommended to pre-heat the engines, as the mechanical stress on engine components is much lower for warm starts than for cold starts.

The power price proved to be a key factor in the profitability of providing control energy reserves. Figure 8 shows the development of the average approved power price at the market for positive secondary control energy reserves for peak times (08:00-20:00 on weekdays excluding public holidays) and off-peak times (rest of the time) during the simulated period [26].

These prices fluctuate considerably and are almost impossible to predict. There are times when no revenue can be generated by the power price at all. This was especially the case during the last three simulated months, which led to negative economic results when providing control energy reserves, as shown in Fig. 4. It is not recommended to participate in markets for control energy reserves when no revenue can be generated by the power price.

The installed biogas storage capacity proved to be sufficient to provide positive secondary control energy reserves while simultaneously producing biomethane during the simulated period. Two additional parameters that should be considered in this context are the maximum outflow rate and pressure drop in the biogas storage. High outflow rates can lead to sudden pressure drops in the storage if the supporting air blower is not designed to be powerful enough. The dimensioning of the gas pipes must also be considered: the maximum outflow rate in the simulated scenario was around $1100 \mathrm{~m}_{\mathrm{N}}^{3} \cdot \mathrm{h}^{-1}$. A comparison with manufacturer data showed that the investigated biogas plant's gas lines and biogas storage are adequately dimensioned for this volume flow rate. However, this is not necessary the case for other biogas plants that consider the provision of control energy reserves. Figure 9 shows the results of a sensitivity analysis regarding the profitability of an investment in a heat storage unit with a volume of $5 \mathrm{~m}^{3}$. Profitability mainly depends on heat and investment costs. The results reveal that lower heat costs (and therefore

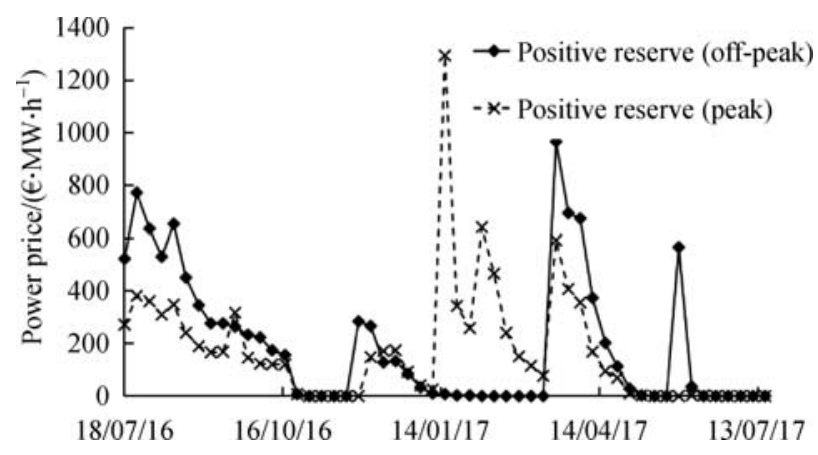

Fig. 8 Development of power price at the market for positive secondary control energy reserves during the simulated period

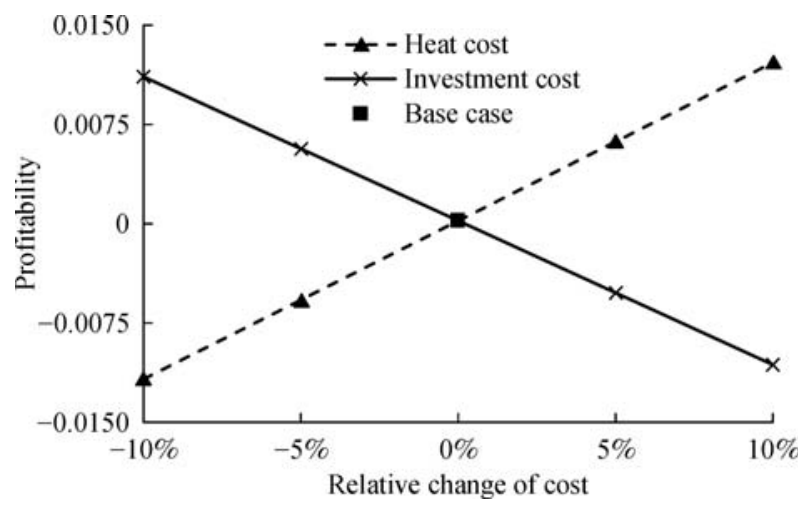

Fig. 9 Results of a sensitivity analysis on heat and investment costs for a hot water tank with a volume of $5 \mathrm{~m}^{3}$

lower investment revenues) or higher investment costs can lead to a negative profitability.

\section{Conclusions}

This work assessed the technical and economic effects of providing control energy reserves with a biomethaneproducing biogas plant from Austria. A model of the investigated plant was developed and proved suitable for dynamic simulation of flexible biogas plant operation. One year of operation was simulated ex-post assuming participation in the market for positive secondary control energy reserves. The simulation was compared to the plant's current state of operation. The findings showed that the installed biogas storage capacity and gas lines are sufficiently dimensioned to provide control energy reserves while simultaneously producing biomethane.

An economic assessment revealed that participation in the market for secondary control energy reserves was profitable in most of the simulated months, except for months when the power price was low. Moreover, the results of a sensitivity analysis showed that start-up costs considerably affect profitability and should be minimised. A volume of $5 \mathrm{~m}^{3}$ for a heat storage unit proved economically most viable during a cost efficiency analysis, with a profitability of 0.0002 . Lower heat costs or higher investment costs might lead to a negative profitability.

Acknowledgements This study was conducted over the course of the Bio (FLEX)Net project (project number D16621150400) that is supported by the Austrian Research Promotion Agency (FFG). Open access funding provided by TU Wien (TUW).

Open Access This article is licensed under a Creative Commons Attribution 4.0 International License, which permits use, sharing, adaptation, distribution and reproduction in any medium or format, as long as you give appropriate credit to the original author(s) and the source, provide a link to the Creative Commons licence, and indicate if changes were made. The images or other third party material in this article are included in the article's Creative Commons licence, unless indicated otherwise in a credit line to the material. If material is not included in the article's Creative Commons licence and your 
intended use is not permitted by statutory regulation or exceeds the permitted use, you will need to obtain permission directly from the copyright holder. To view a copy of this licence, visit http://creativecommons.org/licenses/by/4.0/.

\section{References}

1. European Commission. Communication from the commission to the European Parliament, the Council, the European Economic and Social Committee, the Committee of the Regions and the European Investment Bank: A framework strategy for a resilient energy union with a forward-looking climate change policy. Energy Union Package (COM(2015) 80 final). 2015, 14-15

2. European Environment Agency. Trends and Projections in Europe 2017: Tracking Progress Towards Europe's Climate and Energy targets. Luxembourg: Publications Office of the European Union, 2017, 27-29

3. Energy Control Austria. Green Power Report. 2017, 64-66 (in German)

4. Droste-Franke B, Schneider J P, Paal B P, Schreurs M, Rehtanz C, Ziesemer T, Sauer D U. Balancing Renewable Electricity. Heidelberg: Springer, 2012, 61-82

5. Bost M, Aretz A, Hirschl B. Flexible use of biogas as a key element for the integration of renewable energy into the energy system. Umwelt Wirtschafts Forum, 2014, 22(1): 71-78 (in German)

6. Doehler H, Eckel H, Froeba N, Sven G, Grube J, Hauptmann A, Horlacher D, Horn C, Hofmann M. Benchmark Numbers Biogas. 3rd ed. Darmstadt: KTBL, 2013, 167-173 (in German)

7. Miltner M, Makaruk A, Harasek M. Review on available biogas upgrading technologies and innovations towards advanced solutions. Journal of Cleaner Production, 2017, 161: 1329-1337

8. Hahn H, Krautkremer B, Hartmann K, Wachendorf M. Review of concepts for a demand-driven biogas supply for flexible power generation. Renewable \& Sustainable Energy Reviews, 2014, 29 : 383-393

9. Mauky E, Jacobi H F, Liebetrau J, Nelles M. Flexible biogas production for demand-driven energy supply-Feeding strategies and types of substrates. Bioresource Technology, 2015, 178: 262269

10. Trommler M, Dotzauer M, Barchmann T, Lauer M, Hennig C, Mauky E, Liebetrau J, Thraen D. Flexibilisation of Biogas Plants in Germany. Berlin: DFBEE, 2016, 7-11 (in German)

11. Haering G, Sonnleitner M, Wiedemann L, Zoerner W, Aschmann V. Technical Requirements for Flexible Power Generation with Biogas Plants. Freising: Arbeitsgemeinschaft Landtechnik und Landwirtschaftliches Bauwesen in Bayern e.V. 2013, 3-19 (in German)

12. Gohsen D, Allelein H J. Development of a market-based optimisation model for a demand-based and storable electricity production from biogas. Energy Procedia, 2015, 73: 79-86

13. Lauer M, Thrän D. Biogas plants and surplus generation: Cost driver or reducer in the future German electricity system? Energy Policy, 2017, 109: 324-336

14. Haering G, Baer K, Sonnleitner M, Zoerner W, Braun T. BioStrom -Controllable Power Generation with Biogas Plants. Final project report. 2015, 68-97 (in German)
15. Mauky E, Weinrich S, Jacobi H F, Nägele H J, Liebetrau J, Nelles M. Demand-driven biogas production by flexible feeding in fullscale-Process stability and flexibility potentials. Anaerobe, 2017, 16: $86-95$

16. Hahn H, Ganagin W, Hartmann K, Wachendorf M. Cost analysis of concepts for a demand oriented biogas supply for flexible power generation. Bioresource Technology, 2014, 170: 211-220

17. Barchmann T, Mauky E, Dotzauer M, Stur M, Weinrich S, Jacobi H F, Liebetrau J, Nelles M. Expanding the flexibility of biogas plants - substrate management, schedule synthesis and economic assessment. Landtechnik, 2016, 71(6): 233-251

18. Grim J, Nilsson D, Hansson P A, Nordberg A. Demand-orientated power production from biogas: Modeling and simulations under swedish conditions. Energy \& Fuels, 2015, 29(7): 4066-4075

19. O'Shea R, Wall D, Murphy J D. Modelling a demand driven biogas system for production of electricity at peak demand and for production of biomethane at other times. Bioresource Technology, 2016, 216: 238-249

20. Panos K. Practice Energy Industry: Energy Conversion, Transport and Procurement in the Liberalized Market. Wiesbaden: Springer Vieweg, 2006, 335-339 (in German)

21. Hochloff P, Braun M. Optimizing biogas plants with excess power unit and storage capacity in electricity and control reserve markets. Biomass and Bioenergy, 2014, 65: 125-135

22. Hochloff P, Holzhammer U. Operating concepts for demandoriented power generation from biogas. In: Proceedings of DWA Energietage. Stockhdm: Fraunhofer Publica, 2013, 1-19 (in German)

23. Lauer M, Dotzauer M, Hennig C, Lehmann M, Nebel E, Postel J, Szarka N, Thraen D. Flexible power generation scenarios for biogas plants operated in Germany: Impacts on economic viability and GHG emissions. International Journal of Energy Research, 2017, 41 (1): $63-80$

24. Woess D, Hoeltl W, Proell T, Hofbauer H. Investigation of the startup procedure of a circulating fluidized bed test unit using a commercial steady state simulation tool. In: Proceedings of the 4th European Combustion Meeting. Vienna: European Combustion Meeting, 2009, 1-3

25. Saracevic E, Woess D, Friedl A, Miltner A. Dynamic simulation of a biogas plant providing control energy reserves. Chemical Engineering Transactions, 2017, 61: 931-936

26. Theuretzbacher F, Kiffel G, Walch J, Bauer A, Saracevic E, Miltner A. Biogas in flexible electricity generation - opportunity or false hope? In: Proceedings of the Young Energy Researchers Conference. 2018

27. Austrian Power Grid. Control Area Statistics for 2017. 2017

28. The Association of German Engineers. Economic efficiency of building installations. VDI, 2012, 2067(1): 1-44

29. Institute of Energy and Environmental Technology. Price AtlasDerivation of Cost Functions for Components of Rational Energy Use. Duisburg, 2002, 16-19 (in German)

30. Chemical Engineering. The Chemical Engineering Plant Cost Index. Rockville: Access Intelligence LLC, 2017

31. Zacharias F. Gas Engines. Wuerzburg: Vogel, 2001, 236-237 (in German) 